\title{
Post-tracheostomy tracheo-oesophageal fistula - an unusual presentation
}

\author{
C Deepa, MD; S Kamat, MD; V Ravindran, MD \\ Goa Medical College, Goa, India \\ Corresponding author: C Deepa (drdeepac2007@gmail.com)
}

\begin{abstract}
Tracheostomy, one of the oldest known surgical procedures in the history of medicine, is regularly performed in modern intensive care units. Acquired ulcerative tracheo-oesophageal fistula (TOF) is an uncommon but potentially fatal complication of tracheostomy. We report a case of ulcerative TOF with an unusual yet characteristic presentation, in a ventilator-dependent tracheostomised patient with Guillain-Barré syndrome. It presented as sudden progressive severe abdominal distension that was rhythmic with each ventilator breath. The predisposing factors, clinical features and preventive measures of post-tracheostomy TOF are discussed in this case report. Regular monitoring of tracheal tube cuff pressures and volumes, along with avoidance and treatment of various predisposing factors, are advisable for the prevention of this serious consequence.
\end{abstract}

S Afr J Crit Care 2016;32(1):32-33. DOI:10.7196/SAJCC.2016.v32i1.232

But that life may ... be restored to the animal, an opening must be attempted in the trunk of the trachea, in which a tube of reed or cane should be put; you will then blow into this, so that the lung may rise again and the animal take in air ... (Andreas Wesele Vesalius, 1543)

Tracheostomy is one of the oldest surgical procedures known to mankind. It was mentioned in the ancient Sanskrit script Rigveda, dating as far back as $2000 \mathrm{BC}$. The first successful elective human tracheostomy was performed in 1869 for the administration of general anaesthesia. ${ }^{[1]}$ It is a commonly performed bedside procedure in the modern intensive care unit (ICU); however, it is not devoid of complications. Acquired ulcerative tracheo-oesophageal fistula (TOF) is a rare, but potentially fatal, complication of tracheostomy. We report a case of ulcerative TOF with an unusualyet characteristic presentation, in a ventilator-dependent tracheostomised patient with Guillain-Barré syndrome (GBS).

\section{Case report}

A 28-year-old man with marfanoid habitus was admitted to our ICU with GBS. He was intubated and mechanically ventilated due to respiratory failure. His muscle power did not improve despite intravenous immunoglobulin and he continued to be ventilator-dependent. Surgical tracheostomy using a size 8.0 Portex (Smiths Medical, USA) polyvinylchloride (high volume, low pressure cuff) tracheostomy tube (TT) was performed after 2 weeks. He had anaemia and weight loss despite enteral nutrition through a $12 \mathrm{~F}$ nasogastric (NG) tube. He developed a bronchopleural fistula on the right side following intercostal drain insertion for spontaneous pneumothorax. He acquired ventilatorassociated tracheobronchitis and pneumonia, and worsened into septic shock. His airway pressures were continually maintained below $30 \mathrm{~cm}$ $\mathrm{H}_{2} \mathrm{O}$. The tracheostomy tube was changed every 3 weeks as per the ICU protocol. As there was no cuff pressure manometer available in our ICU, we were unable to monitor the TT cuff pressure accurately. His mode of communication with the unit staff and relatives was through lip, head and neck movements.

From the 76th post-tracheostomy day onwards, there was an audible air leak around the TT cuff and increasing volumes of air seal $(10 \mathrm{~mL}$, increasing to $14 \mathrm{~mL}$ ) were required daily. This raised suspicion of tracheal dilatation; however, bedside radiograph of the neck showed a normal cuff air shadow. On the 83rd post-tracheostomy day, we noticed rapidly progressive abdominal distension with each mechanical breath from the ventilator. The epigastric distension was relieved immediately on opening the proximal end of the NG tube. A clinical diagnosis of TOF was made. A bedside radiograph showed a TT cuff air shadow extending beyond the confines of the trachea and a grossly distended stomach (Fig. 1).

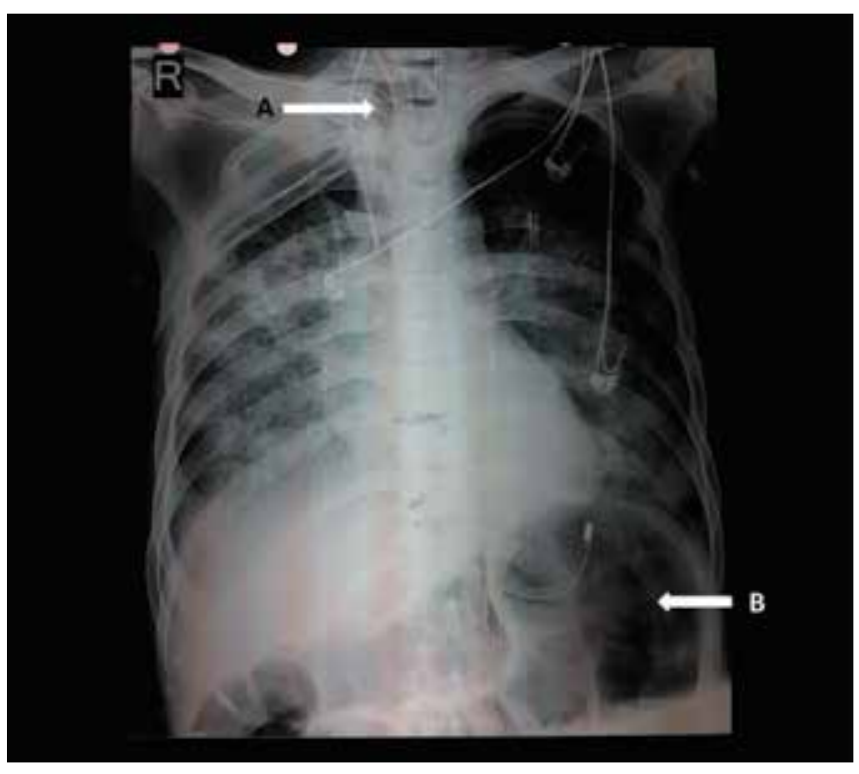

Fig. 1. Radiograph showing: (A) TT cuff air shadow extending beyond the confines of the trachea; and (B) grossly distended stomach.

Fibreoptic bronchoscopy (FOB) revealed a TOF $(3 \mathrm{~cm}$ long and $1 \mathrm{~cm}$ wide) in the right posterolateral tracheal wall, situated distal to the equator of the cuff and extending almost to the tip of the TT (Fig. 2). After removal of the TT, orotracheal intubation with endotracheal tube (ET) size 8.0 was performed under FOB guidance and the cuff was positioned distal to the TOF. The tracheostomy stoma was then closed by suturing. Definitive surgical repair was planned once sepsis was treated. Unfortunately, the patient succumbed to septic shock 10 days after diagnosis of TOF. 


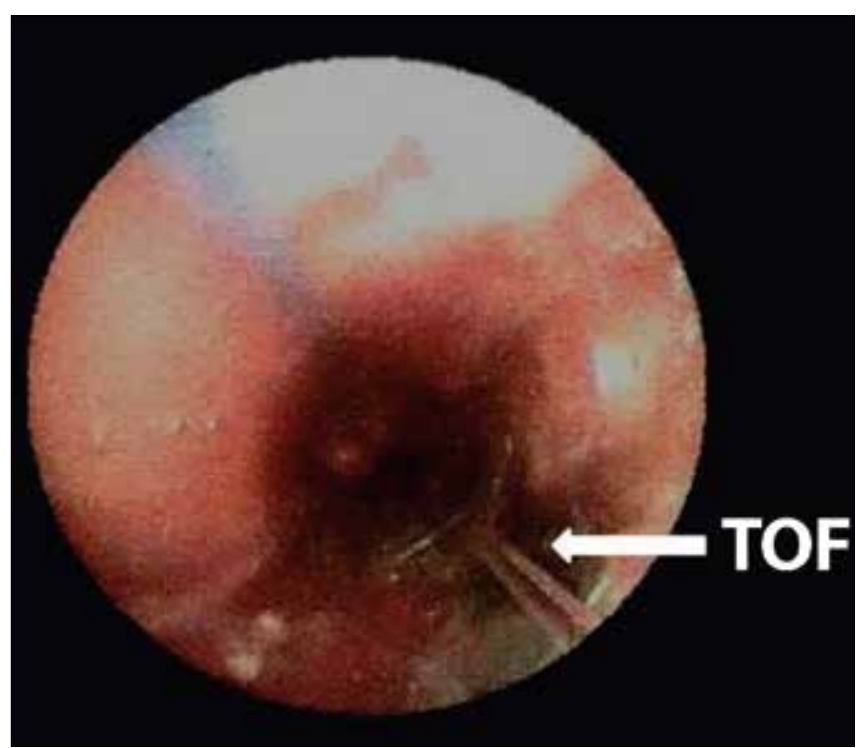

Fig. 2. FOB view of the TOF.

\section{Discussion}

TOF is observed in $<1 \%$ of patients undergoing tracheostomy. ${ }^{[2]}$ Traumatic TOF following injury to the posterior tracheal wall during tracheostomy usually manifests in the first 48 hours following the procedure. Ulcerative TOF that occurs in patients with cuffed TT in situ for prolonged periods usually becomes symptomatic within 4 weeks. It results from tracheal mucosal ischaemia and erosion. This may be due to TT cuff pressures exceeding tracheal mucosal perfusion pressure or due to abrasion of the tracheal wall from movement of the tip of the TT during ventilatory movements, tracheal suctioning and excessive neck movements. The concomitant use of a rigid, wide-bore NG tube can aggravate the injury to the posterior tracheal wall, which gets sandwiched between the inflated cuff and the feeding tube along with the anterior oesophageal wall. ${ }^{[3]}$ Other compounding factors include gastro-oesophageal reflux, tracheobronchitis, malnutrition, hypotension, hypoxaemia, anaemia, diabetes mellitus, metabolic acidosis and steroid therapy ${ }^{[4]}$

In mechanically ventilated patients, the usual manifestations are copious production of respiratory secretions, pneumonia, persistent air leak around the TT cuff, pneumothorax, pneumomediastinum and subcutaneous emphysema. The symptoms and signs will also depend on the situation of the TOF in relation to the TT cuff. A rare but characteristic sign of TOF is the rapid onset of severe epigastric distension, which may be rhythmical with each positive pressure breath from the ventilator. ${ }^{[5]}$ This usually occurs when the TOF is situated below the level of the cuff. This can result in massive abdominal distension with devastating consequences. The need for high cuff inflation pressures, increasing minimal occluding cuff volumes (more than $10 \mathrm{~mL}$ of air) and unexplained persistent air leak around the TT cuff should raise concerns about tracheal dilatation and TOF.

FOB is the gold standard for the diagnosis of TOF. Postero-anterior radiographs of the neck and superior mediastinum may show marked bulging of the cuff beyond the normal confines of the trachea. A special TT with the cuff positioned distal to the fistula may help to re-establish adequate ventilation and prevent soiling of the tracheobronchial tree. ${ }^{[6]}$ Feeding can be managed through gastrostomy or jejunostomy tube.

Regular monitoring of tracheal tube cuff volume and pressure is important. It is advisable to maintain cuff pressures below $20 \mathrm{~cm} \mathrm{H}_{2} \mathrm{O}^{[7]}$ and avoid using more than $8 \mathrm{~mL}$ of air for cuff inflation. ${ }^{[8]}$ Routine cuff deflation and re-inflation are no longer recommended. ${ }^{[7,9]}$ Proper placement of the tracheostomy and tracheostomy tube, use of thin-walled cuffs to minimise movement of the tracheostomy tube relative to the trachea and initiation of weaning as early as possible may help in curtailing trauma to the trachea. Conscious and well-orientated tracheostomised patients should be educated and advised about avoiding excessive neck movements. Measures to minimise gastro-oesophageal reflux, such as head-end elevation to $30^{\circ}$, post-pyloric feeding, administration of enteral feeds as continuous infusion and use of prokinetics, should be implemented. NG tubes, if used, should be small and soft and removed as soon as they are no longer indicated. Predisposing factors such as hypotension, hypoxaemia, anaemia, infection, malnutrition and metabolic acidosis should be prevented and, if present, addressed early.

\section{Conclusion}

TOF is a rare but potentially fatal complication of tracheostomy. Rhythmic and rapid distension of the epigastrium, though unusual, is a dangerous manifestation of TOF. Regular monitoring of tracheal tube cuff pressures and cuff volumes is advisable for the prevention and early recognition of this adverse event.

\footnotetext{
References

1. Delaney A, Bagshaw SM, Nalos M. Percutaneous dilatational tracheostomy versus surgical tracheostomy in critically ill patients: A systematic review and meta-analysis. Crit Care 2006;10(2):1-13. DOI:10.1186/cc4887

2. Epstein SK. Late complications of tracheostomy. Respir Care 2005;50(4):542-549.

3. Diddee R, Shaw IH. Acquired tracheo-oesophageal fistula in adults. Cont Educ Anaesth Crit Care Pain 2006;6(3):105-108. DOI:10.1093/bjaceaccp/mkl019

4. Sanwal MK, Ganjoo P, Tandon MS. Posttracheostomy tracheoesophageal fistula. J Anaesthesiol Clin Pharmacol 2012;28(1):140-141. DOI:10.4103/0970-9185.92478

5. Harley HR. Ulcerative tracheo-oesophageal fistula during treatment by tracheostomy and intermittent positive pressure ventilation. Thorax 1972;27(3):338-352. DOI:10.1136/thx.27.3.338 6. Hydri AS. A modified endotracheal tube serving as a long tracheostomy tube. Internet $J$ Otorhinolaryngol 2006;6(1).

7. Hameed AA, Mohamed H, Al-Mansoori M. Acquired tracheoesophageal fistula due to high intracuff pressure. Ann Thorac Med 2008;3(1):23-25. DOI:10.4103/1817-1737.37950

8. Make BJ, Hill NS, Goldberg AI, et al. Mechanical ventilation beyond the intensive care unit: Report of a consensus conference of the American College of Chest Physicians. Ches 1998;113(5):289S-344S. DOI:10.1378/chest.113.5_supplement.289s

9. Powaser MM, Brown MC, Chezem J, Woodburne CR, Rogenes P, Hanson B. The effectiveness of hourly cuff deflation in minimizing tracheal damage. Heart Lung 1976;5(5):734-741.
} 